\title{
Cultura \& inovação em organizações: limites teórico-metodológicos na prescrição de rotinas administrativas ${ }^{1}$
}

\section{Culture \& Innovation in Organizations: theoretical and methodological limitations in prescribing administrative routines}

\section{Cultura e innovación en organizaciones: limites teórico-metodológicos en la prescripción de rutinas administrativas}

Luciano D'Ascenzi, técnico superior da Agência Estadual de Regulação dos Serviços Públicos Delegados do Rio Grande do Sul (AGERGS). Endereço Profissional: Av. Borges de Medeiros 659, $13^{\circ}$ andar, Porto Alegre - RS - 90020-023 - Brasil. Telefone: (51) 3288-8877.

URL da Homepage: http://www.agergs.rs.gov.br/. E-mail: dascenzi@agergs.rs.gov.br.

Luciana Leite Lima, professora do Departamento de Sociologia da Universidade Federal do Rio Grande do Sul (UFRGS). Endereço Profissional: Av. Bento Gonçalves 9500, Prédio 43311, Porto Alegre - RS - 91509-900 - Brasil. Telefone: (51) 3308-6641. URL da Homepage:http://www.ufrgs.br/ifch. E-mail: lucianaleitelima@gmail.com.

\section{RESUMO}

O presente ensaio teórico apresenta uma abordagem comparativa entre os conceitos de cultura e cultura organizacional, respectivamente, da antropologia e da teoria geral da administração. O diálogo explicita particularidades, possibilidades e limites aplicativos frente às duas procedências. Sugere-se um enfoque metodológico intermediário, complementar às análises e às práticas econômicas hegemônicas, com a inclusão de mais elementos relacionais presentes nos contextos de ação das estruturas locais. Indica-se a necessária incorporação da produção teórico-metodológica em Ciências Sociais que, com a pesquisa empírica, vem demonstrando possibilidades de apreensão da dinâmica cultural junto aos mais diversos loci de estudo. A proposta configura esforço de colaboração entre as mais diversas áreas das Ciências Sociais.

Palavras-chave: Cultura; Inovação; Mudança Social.

\section{ABSTRACT}

This theoretical essay presents an comparative approach between the concepts of culture and organizational culture respectively, anthropology and general management theory. The dialogue explains particularities, possibilities and application limits facing the two origins. It is suggested an intermediary methodological approach, complementary to the analysis and hegemonic economic practices, with the inclusion of more relational elements in the contexts of action of local structures. It is indicated the necessary incorporation of the theoretical and methodological production in social sciences, which, with the empirical research, has been

\footnotetext{
${ }^{1}$ Artigo submetido em 11/07/2014, revisado em 11/08/2014, aceito em 13/08/2014 e divulgado em 01/12/2014 pelo Editor João Carlos Hipólito Bernardes do Nascimento, após double blind review.
}

GєCont, v. 1, n. 2, Floriano-PI, Jul-Dez. 2014. 
demonstrating possibilities of apprehending cultural dynamics along the various loci of study. The proposal configures a collaborative effort between several areas of the social sciences.

Keywords: Culture; Innovation; Social Change Reform.

\section{RESUMEN}

Este teórico ensayo presentes un enfoque comparativo entre los conceptos de cultura y cultura organizacional, respectivamente, de la antropología y de la teoría general de la administración. El diálogo explicita particularidades, posibilidades y límites aplicativos frente a las dos procedencias. Se sugiere enfoque metodológico intermediario, complementar a los análisis y a las prácticas económicas hegemónicas, con la inclusión de más elementos relacionales presentes en los contextos de acción de las estructuras locales. Se indica la necesaria incorporación de la producción teórico-metodológica en ciencias sociales que, con la investigación empírica, viene demostrando posibilidades de aprehensión de la dinámica cultural junto a los más diversos locos de estudio. La propuesta configura esfuerzo de colaboración entre las más diversas áreas de las ciencias sociales.

Palabras-claves: Cultura. Innovación. Cambios sociales.

\section{INTRODUÇÃO}

esde a década de 1980, cresce a inquietação em face à inexistência de um

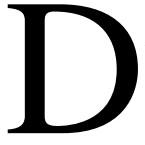
paradigma disciplinar adequado ao que pôde ser chamado "Era do Conhecimento". Tratar-se-ia da época em que o tema da mudança alcança centralidade nas Ciências Sociais em geral, conquistando relativa autonomia transdisciplinar. Assim, a instabilidade das estruturas organizacionais vem recebendo toda sorte de tratamentos científicos específicos.

Em meio ao conjunto de crises paradigmáticas, toma corpo o conceito de "cultura organizacional" junto aos enfoques prescritivos de base comportamental, comumente agrupados sob a denominação de Desenvolvimento Organizacional (CHIAVENATO, 1999; MOTTA; VASCONCELOS, 2009). Em cujo interior, as discussões são trazidas por meio de fortes descrições, rápidas e constantes mudanças sociais enfrentadas pelas empresas.

Mais recentemente, em vista da perenidade e do amadurecimento do tema da mudança, no qual se insere o conceito de cultura organizacional, a conjuntura disciplinar descrita desdobra-se e torna-se mais complexa. Nesse quadro, os objetivos organizacionais clássicos são crescentemente requalificados e identificados com o imperativo da inovação, tida como a estratégia mais adequada à transformação do cenário de ameaças em oportunidades.

Dado o contexto empírico-científico, este artigo busca destacar, comparativamente, as respectivas origens e possibilidades relacionais ativadas a partir de duas diferentes conceituações em cultura, a partir da antropologia social vis-à-vis à encontrada na teoria do desenvolvimento organizacional. Isso, tendo em mente enveredar por questões de ordem teórico-metodológicas, examinando sua adequação à prática administrativa, objeto último de nossa preocupação.

Desse modo, o resgate das matrizes teóricas, que fundamentam os enfoques particulares, será utilizado para indicar qual é a possibilidade de manuseio dos elementos conceituais formadores dos contextos de ação específicos, quando as estruturas 
organizacionais são reproduzidas, quando sofrem o risco da mudança. Trata-se, portanto, de um esforço que tenta discutir a utilidade prático-metodológica da definição de cultura, assim condicionada às novas necessidades gerenciais em situações específicas.

\section{FUNCIONALIDADE E CONTEXTO DE MUDANÇAS}

A realidade dos anos 1970 passou a exibir novo contexto, cuja necessidade de entendimento explicitava uma série de limitações teórico-metodológicas dos enfoques estruturalistas. Em meio a essa nova ordem de coisas, nos anos 1980, germina a apropriação do conceito de cultura junto à Teoria Geral da Administração (TGA), campo de conhecimento dedicado à aplicação de teorias em Ciências Sociais para a solução de problemas administrativos.

Tal realidade pode ser explicitada a partir de toda uma sequência de eventos ambientais externos às organizações (seguidos choques de oferta, crise do Welfare State, desregulamentação, concentração e consolidação dos mercados) que vêm se revelando consistentes no longo prazo e, mais especificamente, pelo sucesso econômico das empresas japonesas nesse cenário de acirramento da concorrência mundial. Um fato justificado com base nas características culturais japonesas - harmonia, coesão e a ideia da empresa como uma grande família (PÉPIN, 1998). Desde então, tais transformações vêm significando intermináveis reestruturações organizacionais, ora preventivas, ora adaptativas.

No plano empresarial, as seguidas reestruturações, por vezes motivadas por fusões e aquisições, têm demorado sobremaneira na tentativa de harmonizar os ideais de eficácia e eficiência em meio às diferenças e choques de mentalidades internas à organização, bem como aos inevitáveis conflitos decorrentes. Uma nova gama de diversidade complicadora à intencionalidade funcional da gestão.

O início desse movimento conta com registros bibliográficos que, de alguma forma, vêm pregar filosofias administrativas radicais. Destacam-se as que vieram considerar a relevância de aspectos culturais; que apresentaram alguma "explicação" para o sucesso ou insucesso dos modelos nacionais em evidência. Ilustrativamente: Hofstede (1980), Ouchi (1981), Pascal e Athos (1981), Deal e Kennedy (1982), Peters e Waterman (1982), Schein (1985).

Em meio à inequívoca contribuição, quase tudo passou a ser dito, tendo em vista a pretensão de diagnosticar a cultura de uma empresa. O primeiro ponto questionável é o uso do conceito no singular, numa possível tentativa de ainda englobar a cultura no mesmo tipo de racionalidade utilitária que costuma caracterizar as visões da organização e do indivíduo. Há soluções que oferecem propostas de mudança cultural em direção à criação de uma "cultura forte e/ou verdadeira", capaz de causar mudanças gerenciadas de performance.

Essas primeiras abordagens visavam explicar as mudanças trazidas pelos novos tempos, unindo o conhecido ao desconhecido. Assim, enquanto pioneiras, foram presas do método e de limites conceituais consagrados, conservando a utilização exclusiva do elemento funcionalista nos mesmos moldes dos enfoques que procuravam atualizar ou substituir. Consequentemente, as abordagens logravam algum sucesso explicativo, mas não avançaram na criação de instrumentos gerenciais.

Passado o modismo das novas contribuições, a consolidação temática pode ser constatada junto aos manuais da TGA em campo específico, a Teoria do Desenvolvimento 
Organizacional. Contudo, mantida a limitação conceitual, não houve avanços significativos. Evidência disso é que, mesmo decorridas três décadas, pouca instrumentalidade restou até os dias de hoje, além das pesquisas sobre "clima organizacional".

Ilustrativamente, Chiavenato (1999, p. 323) afirma que "o clima organizacional constitui o meio interno de uma organização, a atmosfera psicológica característica em cada organização [...] está ligado ao moral e à satisfação das necessidades humanas dos participantes". A análise da ferramenta aponta para a matriz behaviorista, o que indica impossibilidade de avanço para além da percepção de elementos conceituais funcionalistas, já excessivamente explorados. Por seu turno, o exame da prática revela espécie de pesquisa de opinião junto ao corpo de colaboradores, a partir de questionário, com perguntas fechadas elaboradas pela gestão. De modo geral, tais pesquisas formam conjunto que reza, como primeiro passo, a fixação de parâmetros apriorísticos obtidos por intermédio da rígida definição das grandezas empregadas em suas análises (D’ASCENZI, 2010).

Concluímos que o empecilho ao desenvolvimento da temática prende-se ao tratamento da cultura em termos exclusivamente funcionalistas, alijando-a dos demais elementos conceituais presentes nos contextos de ação. A rigor, implicaria criações modelares tendentes a marginalizar segmentos explicativos, sob as denominações de resto, resíduo ou erro, definindo-os conceitualmente como "irracionais" (SIMON, 1979) ou como se tudo o mais restasse constante.

\section{FUNCIONALIDADE E CONCEITUAÇÃO EM CULTURA}

Este item analisa os limites explicativos relativos ao tratamento conceitual de cultura encontrado na Teoria do Desenvolvimento Organizacional da TGA. A diversidade de significados dos objetos culturais, característica dos objetivos de estudo em cultura, é invisível às análises funcionais. Sob essas amarras, a gestão é induzida a confiar excessivamente na introspecção e na lógica na consecução do processo decisório.

Ocorre que qualquer significação apriorística das categorias organizacionais tem apenas o efeito de ocultá-las ou marginalizá-las, impedindo a percepção e o gerenciamento da polissemia local, esta apoiada em culturas internalizadas pela organização. Ao mesmo tempo, a mera reafirmação de significados oficiais resultante desse modus operandi, ao ensejar programas que busquem eliminar a "cacofonia" nos processos de comunicação, pode resultar na marginalidade de possíveis padrões emergentes de significação. Um processo que vem alijar a gestão das possibilidades de exploração de recursos internos à guisa de modelos em "gestação espontânea".

Ignorar os demais elementos relacionais que formam os contextos de ação significa segregar parcela expressiva do objeto de pesquisa e inaugura a possibilidade de marginalizar as demais lógicas presentes, então classificadas como "irracionais". Ademais, as pesquisas demonstram que, frequentemente, muitos resultados são explicados por meio de ajustes voluntaristas, realizados intuitivamente por algum colaborador tão zeloso quanto desobediente ao modelo implementado (D'ASCENZI, 2006, 2010).

Sob a égide das teorias do Desenvolvimento Organizacional são agrupadas perspectivas que tratam a cultura em termos exclusivamente funcionalistas, pouco adiantando remendá-la com o conceito de clima organizacional. Assim, é possível encontrar manuais de administração que descrevem a mudança da cultura organizacional como o equivalente à inserção de novas atitudes, percepções, expectativas, mentalidades, habilidades ou resultados; 
num grupo pré-qualificado como sistema orgânico, definido como flexível e participativo, em contraposição a mecânico e repressivo (CHIAVENATO, 1999).

A necessidade de alguém "que dê o sangue" em vista da lacuna teórica pode ser visualizada em diversas obras que, de resto, pouco avançam em relação a Schein (1985). Mais especificamente, na explicação de um professor em comportamento organizacional da Harvard Business School, observa-se:

\begin{abstract}
Nesse contexto [de futuro em construção], o líder aparece como figura central, como variável independente. O novo líder em todos os níveis e em todos os campos do trabalho humano é, na realidade, um construtor da cultura organizacional [...] Construir e manter uma cultura de trabalho eficaz, uma cultura organizacional saudável, significa eliminar as barreiras da produtividade, por um lado, e a desconfiança e os medos, por outro. Em sentido positivo, é criar e promover sistematicamente em todo o pessoal da organização a lealdade, confiança, vitalidade, participação, comunicação, valores e congruências nas condutas. (SOTO, 2005, p. 233).
\end{abstract}

A obra faz um percurso de temáticas características da psicologia organizacional, numa sequência que vai do comportamento à percepção, da aprendizagem à motivação. Por fim, inicia um trajeto peculiar nos capítulos de nome $O$ Grupo e Liderança e Estilos de Comando, mas deixa o leitor rigoroso intrigado em Gestão da Mudança. Nela, a análise behaviorista não tem como enfrentar a polissemia, uma das características mais importantes da dinâmica da mudança, tornando-se vítima das próprias contradições: "A resistência à mudança, o medo ou a relutância em fazê-la são problemas cotidianos nas empresas [...] Por trás de tanta relutância às mudanças estão os pensamentos distorcidos na mente das pessoas" (SOTO, 2005, p. 259). Em seguida, o autor explica que "a mudança se inicia dentro e a partir de cada uma das pessoas que formam essa organização" (SOTO, 2005, p. 272), mas, então diagnostica:

[...] por que nos custa tanto aceitar o processo de mudança? Porque nos obriga a mudar crenças arraigadas no mais fundo de nossa mente e nos cria a sensação de insegurança e angústia que aumentam a percepção da defasagem entre o que temos gravado e a informação que interpretamos a partir do ambiente. (SOTO, 2005, p. 288).

Delimitando nossa construção crítica, percebe-se que o exclusivismo funcionalista não é um problema em si. De fato, desde que não se pretenda utilizá-lo afora seu real alcance teórico-conceitual, suas análises mostram-se imprescindíveis na administração de coisas e pessoas, cujo limite material encontra-se demonstrado pela sequência de suas cadeias causais. Mesmo porque, salvo os casos relacionados à mudança, as matrizes teóricas utilitaristas e comportamentais vêm oferecendo tratamento eficaz, empiricamente testado.

Todavia a mesma eficácia não pode ser alcançada ao buscar-se estender suas cadeias de causa e efeito para além das possibilidades dedutivas. Chama-se atenção para demandas gerenciais, não contempladas por esse instrumental, caracterizadas pela necessidade de entendimento de problemas ligados à mudança, cujo entendimento depende de explicações que vão adiante das descrições funcionais, por meio de elementos conceituais complementares. Exatamente aqueles que, na prática, tendem a ser inseridos informalmente por voluntaristas ciosos por resultados objetivos. Uma solução que, de roldão, nos traz novo perigo.

GєCont, v. 1, n. 2, Floriano-PI, Jan-Jun. 2014. 
Afinal, se o líder é o "construtor da cultura", conforme Soto (2005), nada parece impedi-lo de estabelecer racionalidades oficiais, solapando as demais formas de entendimento; nem é incomum encontrar classificações que busquem algum nível de exclusão da diversidade, empreendidas a partir da identificação de desviantes, como portadores de resistência ao processo de mudanças ou, até mesmo, como espécies de patologia (FOUCAULT, 1983). Não é de todo incomum encontrar bibliografia em gestão de mudanças que aponte para princípios claramente etnocêntricos, ora em nome da evolução humana, ora contra possíveis "eliciadores de resistência coletiva".

Numa das obras mais emblemáticas em qualidade (DEMING, 1990), encontra-se um capítulo intitulado Doenças e Obstáculos. Nele, o autor "excomunga" algumas práticas relatadas como intrinsecamente nocivas. No entanto, o conjunto da obra insiste na impossibilidade de utilização de soluções prontas. No lugar disso, aconselha o emprego de princípios aplicados em acordo às especificidades de cada realidade.

Mesmo o propalado clima de inovação necessita de algum espaço para a autonomia do pensamento, especialmente no que diz respeito ao que há de mais produtivo e gerenciável, a procura por interlocução. Afinal, quais traços culturais seriam produzidos num ambiente em que a "verdade" viesse da posição hierárquica? Onde não houvesse abertura para discussões com o mainstream? A resposta parece fácil e tem expressão na cultura popular brasileira: tomada a decisão quanto a uma nova "norma" até então estranha ao meio, "manda quem pode, obedece quem tem juízo". Afora isso, restariam os doentes e os criadores de caso, sem capacidade de discernimento.

Sintomaticamente, frente a problemas cuja compreensão necessite ultrapassar o funcionalismo vigente, mas que não encontre voluntarista interno ao grupo, algumas instituições optam pela contratação de consultorias externas. Comumente, trazem solução pronta; as melhores obtêm diagnóstico extraído junto à "prata da casa" que, finalmente, encontra meio de comunicar suas ideias, mas que apenas assiste a troca de uma rigidez por outra; bem pior quando o exame aponta para as famosas "falhas de comunicação" que, não raro, cedem lugar à "existência de ruídos amplificados por indivíduos problemáticos". Este, inadvertidamente, é um exercício de poder proveniente de avaliação isolada, pessoal e descontextualizada.

Afinal, referimo-nos a processos baseados em metodologia que reza o encaminhamento de problemas por meio de encadeamento de funções: um cargo (novo ou vago) fora criado impessoalmente e precisa ser preenchido; um novo colaborador é recrutado, selecionado e treinado, percebendo incentivos particulares, tendo seu desempenho e permanência avaliados individualmente em função do cargo. Quando assim funciona, a cadeia de causa e efeito apresenta seus méritos organizacionais frente às legítimas necessidades de permanência estrutural e seus processos. Entretanto, pensar que seja possível encaminhar situações de mudança, a partir desse único elemento conceitual, é apenas um exercício de reducionismo, cuja crença sobrevive, conforme tratado, graças ao voluntarismo de quem tenha "micropoderes" para, informalmente, ampliar o conjunto relacional do modelo funcional implementado. Algo que pode redundar tanto num "apagar de incêndio" quanto numa "caça às bruxas", em acordo ao contexto e aos humores da liderança de ocasião.

Conforme avaliado anteriormente, a análise funcionalista não apresenta problemas ao tratar situações de permanência das estruturas sociais e estabilidade dos papéis desempenhados. Para tais situações, a ampliação conceitual em cultura seria uma espécie de desperdício. Entretanto, nas situações em que a mudança, induzida ou não, adquira importância, a ampliação do horizonte analítico, com a inclusão do ambiente externo, precisaria caminhar em direção à incorporação de elementos relacionais exógenos aos 
modelos funcionais tradicionalmente utilizados. Esse encaminhamento passa pela relativização do tratamento universal frente às categorias tratadas.

Entende-se que essa questão precisa ser enfrentada pela TGA. Afinal, se a mudança tem importância, conforme demonstrado nos textos em desenvolvimento organizacional, a teoria precisa refletir esse estado e suas consequências: "cada organização deve ser percebida em sua singularidade e dentro do universo que a circunscreve" (WOOD, 1995, p. 3). Indubitavelmente, esta seria uma das principais características de uma metodologia pertinente a tais casos, com a devida adequação da teoria à prática.

Finalmente, em meio à temática da mudança, não é incomum remeter a questão a uma possível "fronteira disciplinar". O reconhecimento da dificuldade é etapa decisiva no encaminhamento do problema. Nesse sentido, invoco um texto coletivo que remete a mudança cultural ao que seria o trabalho de um "antropólogo social ou organizacional". Contudo, mesmo passados 15 anos entre as publicações, o texto ainda identifica tal tarefa com a metodologia encontrada originalmente em Hofstede (1980).

\footnotetext{
A dificuldade de se estabelecerem parâmetros culturais que sejam válidos para toda e qualquer sociedade explica, em parte, a escassez de estudos dentro dessa vertente [mudança organizacional]. Além disso, o estudioso de cultura organizacional deve estar sempre atento para não cair na armadilha do etnocentrismo. (WOOD, 1995, p. 33).

O método antropológico, que serve de base para o estudo da cultura organizacional, requer uma ruptura radical com a crença de que existe um centro do mundo, ou que algumas culturas são mais avançadas ou evoluídas que outras. [...] Toda cultura possui uma lógica própria, que deve ser compreendida a partir dela mesma. (WOOD, 1995, p. 34).

[...] conhecer melhor e respeitar a cultura onde se pretende operar pode representar uma vantagem significativa para a corporação. (WOOD, 1995, p. 37).

O meio ambiente não pode mais ser considerado algo externo às organizações. Sua influência é nítida nos valores, atitudes e comportamentos das pessoas que as compõem e tem reflexos nos processos decisórios e nas formas de gestão. (WOOD, 1995 , p. 54).
}

Em Wood (1995), os autores tratam dos problemas advindos do etnocentrismo no âmbito do ambiente que cerca as organizações. No conjunto, a obra faz menção à antropologia, mas não penetra em sua história para encontrar a resposta ao problema levantado. Se o fizesse, descobriria que o encaminhamento se deu por meio de discussões em relativismo cultural que, repentinamente, marcou a superação de alguns limites importantes internos à matriz funcionalista junto àquela disciplina. Assim, evidenciaria o desperdício de tempo em procurar reinventar a roda, em vez de apropriá-la naquilo que possa redundar em nova contribuição teórico-metodológica à prática administrativa.

\section{ORIGENS E DESENVOLVIMENTO DO CONCEITO DE CULTURA}

A "sociedade" não é uma entidade e não tem uma presença espaço-temporal; ela existe apenas como práticas sociais reproduzidas em uma diversidade indefinida de meios. (GIDDENS, 1997, p. 21). 
No ambicioso e reconhecido trabalho citado, Giddens oferece uma série de reflexões integradas sobre o pensamento social, num esforço que permite resgatar o contexto histórico da formação de alguns paradigmas e suas respectivas matrizes teóricas funcionalistas. Assim, entre os detalhes do estabelecimento das fronteiras disciplinares onde se insere o campo das Ciências Sociais, destaca-se certa influência causada pela filosofia positivista. Nela, ressaltase uma preocupação datada com o status de ciência, consubstanciada pela falsa "ideia de que as ciências naturais e sociais compartilham uma lógica comum e talvez até mesmo uma mesma base metodológica" (GIDDENS, 1997, p. 170).

O autor relata que, até a metade do século passado, podiam-se encontrar trabalhos em Ciências Sociais que procuravam de diversas maneiras se distanciar das ciências do espírito, devidamente afastadas para o campo da teologia. Revelavam, ainda, certo afã por construções contrastantes que, não raro, permitissem-nas imiscuir-se nas ciências da natureza, chegando às raias da obtenção de métricas positivas para suas categorias de análise. Metaforicamente, as cicatrizes de batalha pelo reconhecimento de um campo próprio abundam nas Ciências Sociais, através da diversidade de terminologias que guardam essa relação (organização, estrutura, sistema, mecanismo, equilíbrio etc.). Esse também é o contexto científico, fortemente influenciado pelo Iluminismo e pelo pensamento evolucionista, que caracteriza a gênese e os primeiros desenvolvimentos em cultura.

A cultura tem status privilegiado junto à antropologia desde seus primórdios, e é no interior desse campo que se encontra suas primeiras formulações. A palavra culture foi construída em 1871 - Edward Tylor, em Primitive Culture, propõe o conceito a partir de kultur, do alemão, e civilization, do francês - reunindo duas ideias independentes: de um lado, o espírito humano em sua capacidade criativa artística e sua ligação com a terra natal; de outro, nosso livre arbítrio para modificar e utilizar a natureza. Desde então, o termo vem passando por processo de desenvolvimento teórico-metodológico, cuja mais recente apropriação junto à TGA vem, ao mesmo tempo, realçar potencialidades e solicitar discussões específicas. Aponta-se para certo paralelismo a ser resgatado e explorado.

A gênese do conceito de cultura deu-se em plena sociedade colonial, crescentemente influenciada pela ciência moderna. O colonialismo ditava as relações econômicas e geopolíticas entre as nações, enquanto o pensamento evolucionista proporcionava a legitimação científica e moral para tal, dado o processo de consolidação laica no Estado moderno. Pensava-se na sociedade ocidental como o auge da humanidade. Às outras, classificadas como "primitivas", restava o papel de laboratórios naturais a demonstrarem positivamente as etapas já superadas pelas metrópoles coloniais "civilizadas".

Tal contexto condicionava e estabelecia limites relativos ao "estado da arte" inicial que vinha caracterizar as humanidades. A crença na unicidade sequencial do desenvolvimento social facilitava a construção de tipologias em meio à proliferação de objetos de estudo numa mesma base epistemológica, fossem físicos, sociais ou biológicos. Essa desordem inicial possibilitou construções teóricas que promoveram a indissociação entre natureza e cultura. Assim, também na antropologia, tal qual vem se dando hoje em TGA, tinha-se a falsa ideia de que o trabalho de mapear uma cultura era iniciado com a definição apriorística das grandezas a serem observadas e quantificadas a posteriori. Mais tarde, tais providências iniciais seriam suprimidas por se revelarem presas das falácias etnocêntricas evolucionistas. Hoje, há clareza sobre os problemas advindos da indevida transposição de categorias culturais de um "lugar" para outro (GEERTZ, 2002).

Trata-se da ancestralidade, que explica muitas das características das Ciências Sociais em geral, e dos estudos em cultura. Estes surgiram simultânea e independentemente, em três regiões distintas do globo - França, Inglaterra e Estados Unidos. Uma ordem de coisas dá 
procedência aos três paradigmas iniciais da disciplina, já evidenciando uma característica distinta em relação às ciências que estudam o mundo material: a concomitância paradigmática (OLIVEIRA, 1988) - talvez o maior complicador para quem empreenda um estudo superficial em cultura.

A superação desse entrave demorou até meados do século $\mathrm{XX}$, em processo iniciado no interior do paradigma culturalista da antropologia, não por acaso, um dos que mais avançaram na positividade dos registros. Com o tempo, a disseminação das discussões em "relativismo cultural" veio possibilitar enorme progresso, sendo levadas às últimas consequências pelos autores pós-modernos ${ }^{1}$, curiosamente, nos mesmos anos 1980.

Como é possível perceber, sem os recursos de comunicação hoje disponíveis, tal consolidação teórica metodológica precisou de algum tempo. Enquanto isso, centenas de definições foram sendo empreendidas, em vista das seguidas inadequações, em face das especificidades dos novos lócus de pesquisa. Um dos registros emblemáticos da guinada metodológica pode ser encontrada em Kroeber e Kluckhohn (1963) de 1952, no qual encontra-se um compêndio com 164 definições para o conceito de cultura.

O mais importante é entender que as definições devem ocupar o lugar de resultado da pesquisa, não uma premissa. E ainda precisa-se da clareza de que, ao contrário do que ocorre nas ciências da natureza, o rigor em estudos sociais pede que se evitem classificações absolutas quanto às diferenças encontradas, e isso tanto na comparação entre grupos quanto entre sociedades distintas. Afinal, normalmente as pessoas refletem, preferem e escolhem uma ação dentre outras igualmente possíveis, sempre em termos relativos. É algo que difere, numa infinidade de aspectos, das células e dos corpos inertes, que seguem leis absolutas e, assim, replicáveis. Desse modo, tem-se que natureza e cultura são complementares. Algo que vem permitir, em termos analíticos, distinção uma da outra.

Retendo as duas ideias, tem-se condições de avançar na discussão em relativismo cultural frente a nossos propósitos. Ele diz respeito à relatividade das comparações, em vez de classificações rígidas formadoras de pares dicotômicos, ou é isso ou é aquilo.

Assim, por exemplo, alternativamente à distinção entre organização formal e informal, o relativismo metodológico veio permitir incorporar a fluidez da realidade à análise. Afinal, na prática, existem mais do que duas possibilidades opostas de classificação. Ou seja, por vezes, apenas uma opção, oficial ou não oficial, não permite descrição fidedigna da realidade que se pretende entender, notadamente quanto aos níveis de oficiosidade presentes.

Especialmente quando são os estados de mudança que importam ao processo decisório, este não pode prescindir de entender e considerar situações limiares correlatas, de resto, sempre presentes. Quaisquer procedimentos que venham a exigir maior nível de precisão empírica não têm como abrir mão da incorporação de outros elementos conceituais contextualmente presentes, além da funcionalidade já tratada em economia ou TGA.

Entretanto, atender a essa exigência relacional inclui a construção de ferramentas inéditas. Trata-se, então, de esclarecer a diferença e a complementaridade de tais elementos explicativos a partir da funcionalidade de situações específicas.

Em A interpretação das culturas, Geertz (1978) nos leva a perceber a sutileza dos elementos conceituais, a partir de um evento tão singelo quanto esclarecedor. A narrativa clarifica a distinção entre os elementos objetivos descritivos (funcionalidade universal) e alguns subjetivos de significado (simbolismo contextual) da realidade tratada. 


\begin{abstract}
Vamos considerar dois garotos piscando rapidamente o olho direito. Num deles, esse é um tique involuntário; no outro, é uma piscadela conspiratória a um amigo. Como movimentos, os dois são idênticos; observando os dois sozinhos, como se fosse uma câmara, numa observação 'fenomenalista', ninguém poderia dizer quais delas seria um tique nervoso ou uma piscadela ou, na verdade, se ambas eram piscadelas ou tiques nervosos. No entanto, embora não retratável, a diferença entre um tique nervoso e uma piscadela é grande, como bem sabe aquele que teve a infelicidade de ver o primeiro tomado pela segunda. $\mathrm{O}$ piscador está se comunicando e, de fato, comunicando de uma forma precisa e especial: (1) deliberadamente, (2) a alguém em particular, (3) transmitindo uma mensagem particular, (4) de acordo com um código socialmente estabelecido e (5) sem o conhecimento dos demais companheiros [...] o piscador executou duas ações - contrair a pálpebra e piscar - enquanto o que tem um tique nervoso apenas executou uma - contraiu a pálpebra. Contrair as pálpebras de propósito, quando existe um código público no qual agir assim significa um sinal conspiratório, é piscar. É tudo que há a respeito: uma partícula de comportamento, um sinal de cultura e - voilá! - um gesto [...] Entretanto, para a câmara, um behaviorista radical ou um crente em sentenças protocolares, o que ficaria registrado é que ele está contraindo rapidamente sua pálpebra direita. (GEERTZ, 1978, p. 16).
\end{abstract}

O trecho desvenda a relatividade dos registros que um método adequado à problemática em cultura deve ser capaz de captar e registrar. Por ora, pode-se ficar com algumas conclusões: (1) a metodologia em mudança não pode prescindir de outros elementos conceituais ligados ao plano simbólico, mas não precisa abrir mão das abordagens funcionalistas, já em vigor e suficientes para controlar e prescrever a continuidade material; (2) categorias culturais prestam-se mais à interpretação do que à prescrição.

\title{
5. TEORIA E PRÁTICA EM CULTURA E INOVAÇÃO
}

Grande parte da bibliografia em inovação tem sugerido a criação de estruturas internas específicas à inovação, tendo em vista os imperativos concorrenciais da "Era do Conhecimento". Assim, as reestruturações passariam a ser editadas perenemente, seja com foco externo (inovações radicais), seja interno (inovações incrementais) (COOMBS; SAVIOTTI; WALSH, 1987). Ou ainda:

\footnotetext{
What do we mean by 'innovation'? Essentially we are talking about change, and our focus in this book is particularly upon technological change. Change of this kind can take two forms - in the things (products/services) which an organization offers, and change in the ways in which they are created and delivered. (TIDD; BESSANT; PAVITT, 2001, p. 6, grifos nossos) ${ }^{2}$.
}

Complementarmente, poucas obras vêm tratando a segunda forma de mudança grifada com a devida propriedade. Enquanto umas apresentam estrutura e conteúdo assemelhados aos manuais de autoajuda, raras conseguem inaugurar aprofundamento e rigor conceitual que apontassem para a necessidade prévia de formulações em "tecnologia social", fundamentais à criação de ferramentas gerenciais efetivas em mudança. Apesar do número reduzido, empreendem trabalho que abre campo de pesquisa fundamental à temática da mudança organizacional em geral e da inovação em particular.

Um sistema tecnológico avançado assentado em um gesto técnico frágil e descartável representa um dos grandes perigos que se apresentam à nova 
sociabilidade [...] O pensamento [neo]schumpeteriano [em voga] [...] desdenhou dessa preocupação. Todo desenvolvimento técnico caminha para um aprofundamento inexorável, em que o aprimoramento organizacional e tecnológico se fortalecem mutuamente. (ANDRADE, 2011, p. 146).

Entretanto, não se trata unicamente de fortalecimento mútuo. Mais do que isso, existiriam limites objetivos à consecução de mudanças calçadas única e exclusivamente em um ou outro aspecto, quais sejam nas "coisas" ou nos "modos" destacados na primeira citação. Tal conclusão pode ser alcançada por caminhos e realidades diferentes.

Do ponto de vista da análise exclusivamente funcional, "coisas" e "modos" ocupariam a função de fatores produtivos integrantes de um dado sistema (micro) econômico. Esse tratamento permite invocar a ciência econômica e, já em seu interior, valer-nos da chamada "lei dos rendimentos marginais decrescentes", cuja explicação consta da diversidade de seus manuais: "Ao aumentar o fator [de produção] $(\mathrm{N})$, sendo dada a quantidade de um fator fixo, a PMg [produtividade marginal] do fator variável cresce até certo ponto e, a partir daí, decresce, até tornar-se negativa" (VASCONCELLOS, 2009, p. 116); “[...] esperar-se-ia normalmente que o produto marginal de um fator diminuísse à medida que mais e mais desse fator fosse utilizado" (VARIAN, 1993, p. 344); “[...] a 'lei dos rendimentos decrescentes' é verdadeiramente uma asserção empírica aproximada da realidade. Não é um teorema [ou] [...] uma proposição lógica [...] É importante notar que nunca foi registrada uma observação empírica contrária" (FERGUSON, 1984, p. 156-157).

Percebe-se que a última assertiva deixa claro que, mesmo reconhecendo a correlação, a microeconomia ater-se-ia à observação funcional da relação entre a grandeza fixa (capital) e a variável (trabalho). Isto é, à teoria não caberia, conceitualmente, trabalhar tal fenômeno, tido como um dado da realidade empírica, da natureza dos objetos de estudo. Ou ainda, poder-seia tratar-se de fronteira disciplinar, delimitadora do universo econômico, que não nos cabe questionar, mas trazer ao exame.

Assim procedendo, apontamos novamente para os casos nos quais a mudança nas relações entre modos e coisas revista-se de relevância gerencial. O encaminhamento desse problema partiria, então, da premissa de que existe uma relação necessária entre ambos, quando empregados como fatores produtivos. Contudo, dado o limite ex-ante, o elemento conceitual funcional pode até descrever, mas não explicar, tal relação. Concluindo, o encaminhamento da questão está para além das possibilidades explicativas dos instrumentais de base funcionalista.

A clareza encontrada nos manuais de economia não está expressa, em grande medida, nos textos em TGA. Em seu interior, os trabalhos da teoria do desenvolvimento organizacional, de matriz funcionalista, arvoram-se tratar problemas que, na verdade, estão fora de alcance conceitual. Para lidar com as situações de mudança, entende-se que outros elementos conceituais presentes nos contextos de ação específicos deveriam ser incorporados à análise. Significa transpor o campo disciplinar, por meio da ampliação da visão do conjunto relacional.

Empiricamente, por suas características tecnológicas, o setor de softwares é emblemático na demonstração dessa mesma relação funcional entre "coisas" e "modos". Em sua formação inicial, até os anos 1990, a "fase cowboy", quando a mesma pessoa executava todas as funções, era calcada na solidão e independência do programador e na produção completamente customizada para cada cliente. Esse know-how não teve como se manter em face da disseminação tecnológica e dos imperativos da produtividade. Em sua substituição, provieram ideais de produção impessoal em série, consubstanciados na construção de "fábricas de software", agora em franco processo de contestação e reconfiguração 
(D’ASCENZI, 2010). Infelizmente, a reflexão e a superação dos problemas vivenciados parecem manter-se exclusivamente sob o cuidado de "especialistas" em rotinas específicas, sem causar questionamento dos pressupostos sociológicos, mas de explicação próxima ao "modelo da lata de lixo" (COHEN; MARCH; OLSEN, 1972), num encontro casual entre problemas e soluções no processo decisório.

Por seu turno, os setores de telecomunicações e de TV a cabo podem vir a ser outro case mal explicado. Estudo inédito da Price Water House Coopers seria nova oportunidade para iniciar alguma reflexão, mas apenas se houver expansão do universo de investigação; algo improvável em nossa sociedade de especialistas. Afinal, à perplexidade de constatações do tipo "se as empresas deixassem o dinheiro no mercado financeiro teriam mais retorno", $65 \%$ dos atores consultados acusaram possíveis peculiaridades do setor: investimentos seriam movidos por necessidades de adequação tecnológica, e não por planos de negócios $\left(\right.$ COLOMBO, 2012, p. B3) ${ }^{3}$. E o que dizer então da crise do subprime, quando os mesmos executivos que levaram suas respectivas corporações à insolvência foram regiamente recompensados com bônus por resultados alcançados? Seria esse o tipo de meritocracia almejado pelo sistema econômico e seus agentes?

Metaforicamente, um pássaro precisa de um par de asas minimamente equilibradas para alçar voo. Afinal, se a teoria social, em geral, abre a possibilidade da diversidade, tanto de possibilidades quanto de combinações, também estabelece a necessária correlação conceitual entre artefatos e seus respectivos sistemas culturais. Do mesmo modo, "the things (products/services) which an organization offers" e "the ways in which they are created and delivered" guardam relação de especificidade sistêmica, relacionando-se intimamente - uma ordem social das coisas que obrigaria o pesquisador da área a perscrutar categorias relacionais específicas, permitindo entender possíveis mudanças institucionais, concomitantemente, nessas duas frentes. Esse espaço, de adequação entre coisas e modos, é o "lugar" de aprofundamento de nossa questão em cultura e mudança. Para isso, volta-se aos textos em inovação.

Embora os trabalhos de Tidd, Bessant e Pavitt (2001) e Andrade (2011) ocupem-se de objetivos e categorias diversas - o primeiro oferece método funcional facilitador de inovações em geral; o segundo dedica-se à análise de casos concretos, analisados, concluindo pela elevação da "autonomia", relacionada ao nível de prerrogativas do(s) agente(s) da inovação e sua(s) estrutura(s) social(is) correlata(s), ao patamar de categoria relevante - ambos constroem seus ideários a partir da problemática em inovação e argumentam que, à inovação, não bastam insights geniais.

Quanto a isso, ainda que tais ideias fossem levadas a sério nas organizações, não raro veem-se potenciais novidades ensejando repulsa e preconceito devido à maneira com que foram executadas. Tais ensaios têm o inconveniente de gerar um juízo de valor incompleto da utilização de práticas e conceitos variados, quando esse julgamento é proveniente de crítica empiricamente fundada, por meio de experiências de sistemas e/ou de práticas mal formuladas, passando a inibir futuras mudanças, desde então estigmatizadas. É uma ordem de coisas corriqueira aos modismos, assistidos por especialistas, assim mal preparados, que vêm dificultar a inovação sobre bases mais sólidas e equilibradas. Mesmo porque a produção de ferramentas baseadas em tecnologias sociais não tem como ser efetivamente operacionalizada por mimetismos e simplificações.

Ironicamente, o uso do termo cultura organizacional junto à TGA, apresentado pelos enfoques para encaminhar soluções em contextos de mudança, não se revela adequado. Especialmente porque, a rigor, a cultura não pode ser entendida como fator de mudança, nem 
manuseada como um hardware passível de alocação ótima. Dois equívocos que acabam por inverter o sentido de sua utilização rigorosa.

Ao contrário desse tipo de utilização, filiamo-nos àqueles que percebem na cultura seu caráter condicionador das mudanças, posto funcionar como mantenedora de identidades e de estruturas sociais previamente existentes, cuja alteração está ligada indissociavelmente à própria reprodução delas (SAHLINS, 1990). A cultura implica certos padrões que limitam possibilidades estruturais passíveis de reprodução local. Assim, para atuar sobre uma cultura, este trabalho defende a necessidade de coletar material empírico, concretamente, usando para tal o trabalho de campo nos "lugares" organizacionais.

Segue-se que a possibilidade de produzir tecnologias sociais, resultantes desse tipo de empreitada, possibilitaria a criação de ferramentas auxiliares aos processos, de mudança gerenciada, demandados pelos imperativos da inovação. Isso permitiria a diminuição do nível de violência e de desperdício, causando impactos positivos sobre a produtividade. Sempre que a mudança organizacional seja relevante, sugere-se esforços de incorporação de conceitos complementarmente à funcionalidade dos contextos de ação a partir de observações in loco.

Primeiramente, haveria pouca utilidade em substituir as análises consagradas às estruturas e aos processos rotineiros, essencialmente funcionais. Mais do que isso, entende-se que as operações repetitivas e, por isso, previsíveis reúnem a grande parcela da realidade organizacional. Aqui, considera-se a adequação inconteste. Não se pode negar que as cadeias de causa e efeito respondem a quase todas as necessidades de análise em tais contextos. Possivelmente, a própria noção de qualidade manter-se-ia intacta, apenas agregando novas categorias de controle, objetivando registrar e encaminhar os prováveis "padrões emergentes" em meio às usuais faltas de conformidade ao padrão de qualidade almejado. Mesmo porque, normalmente, a mudança não é o que importa, mas as operações rotineiras do dia a dia, garantidoras da qualidade escolhida.

Ocorre coisa diversa na formação e criação conjuntural desses mesmos conjuntos, quando a rotina prévia sofre, ativa ou passivamente, impulsos resultantes dos processos de mudança ou de inovação. Aqui, inegavelmente, abre-se espaço significativo para a produção de tecnologias sociais atenuadoras da necessidade de capital de giro e violência, duas fontes de desperdício que costumam preceder os investimentos, em geral, e, particularmente, a mudança de rotinas já sedimentadas. Mesmo para esses casos, não se está pregando revolução alguma. Ao contrário disso, as análises tradicionais restariam intocadas, apenas passando sua produção para novo processo analítico, em que seus registros ocupariam o papel de "matériaprima", a ser refinada e adensada por análise complementar.

Assim, o trabalho inicial, de base funcional, estaria pronto, bastando recheá-lo com os elementos simbólicos relevantes ao processo decisório. Ou seja, nos casos em que a resposta da pergunta da gestão implicasse entender recorrências ou mudanças (in)desejadas (conforme o caso). Somente então, seria aconselhável valer-se de algum tipo de incorporação e adensamento do trabalho de base funcionalista, internamente disponível, como "ponto de partida" da dialogia prático-teórica necessária. Isso por entendermos que um tratamento rigoroso em cultura, a partir das teorias e dos métodos consagrados em Ciências Sociais, viabiliza a incorporação seletiva de mais elementos conceituais explicativos, a partir da base funcional consagrada. Mesmo porque não vemos qualquer utilidade na violência das revoluções ou no desperdício da reinvenção da roda.

Nas Ciências Sociais, destaca-se o método etnográfico utilizado em antropologia. Ele é intrinsecamente interdisciplinar, foi desenvolvido para mapear culturas as mais diversas e permite perceber e incorporar qualquer tipo de elemento conceitual explicativo à realidade pesquisada. Desse modo, além de reunir as condições necessárias, apresenta fácil 
adaptabilidade contextual. No entanto, se o ponto de partida parece mesmo óbvio, o estado da arte em Ciências Sociais, o de chegada ainda se reveste de incógnita, posto resultar de trabalho científico a partir de problemas reais analisados em pesquisas empíricas e desenvolvimentos metodológicos os mais diversos. Nesse sentido, poder-se-ia aventar inúmeras possibilidades, todas construindo suas respectivas incorporações ou dissociações a partir do método citado. Afinal, trata-se de campos de conhecimento distintos, com suas categorias explicativas particulares.

Ainda neste tópico, cabe discutir aquilo que foi denominado como sendo o "ponto de partida", reservando para a conclusão do artigo as considerações acerca das possibilidades de pesquisa e desenvolvimento.

Em se tratando da incorporação de método previamente existente, certo nível de rigor torna-se indispensável à necessária apropriação. Isso é pré-condição à independência que se segue, uma vez tratarmos da transposição da teoria para a prática, dentro do mesmo campo de conhecimento. Assim sendo, a apropriação implica certo custo inicial específico, a título de investimento para o domínio das técnicas e dos pressupostos que consubstanciam a abordagem etnográfica. Um pedágio necessário aos que pretendam seguir o caminho proposto, dando amplitude real ao conceito de cultura organizacional em TGA. Salienta-se a relação custo-benefício por entendermos que a prática tem descuidado da qualidade teórica e, assim, caído em progressivo descrédito, restando aquém de suas potencialidades como ferramenta de gestão.

Nessa perspectiva, na maior parte dos casos, a percepção de que existe uma cultura vem sendo expressa em termos de incerteza, de problema ou, simplesmente, como uma explicação de por que as coisas não funcionaram conforme o esperado. Essa é uma tática que pode ser utilizada tanto para a individualização quanto para a coletivização de responsabilidades, em função inversa às prerrogativas de poder. Assim, busca-se desanuviar a questão, visando a tornar sua utilização menos abstrata e mais instrumental. Reafirmamos que a desordem conceitual não é explicada por falta de maturidade ou de definição formal em meio à temática em cultura. Ao contrário disso, haveria excesso de enunciados prévios e falta de operacionalidade prática. Um estado de coisas que vem apenas atrapalhar o desenvolvimento de pesquisas específicas úteis.

Primeiramente, de posse dos registros funcionais rotineiramente produzidos, dados e teorias demandam movimento dialógico de aproximação e distanciamento para, só então, objetivarem formulação útil ao processo decisório. Isto é, precisam ser lidos e relidos à luz da imaterialidade que caracteriza o simbólico, onde a diversidade é intrínseca. Afinal de contas, então, o que é cultura? Por que esse termo se presta a tantas coisas e causa tanta confusão? Qual seria a origem desse estado de coisas?

A tradição em antropologia permite delinear a cultura de maneira bastante pragmática. Segundo esse campo, em uma aproximação pedagógica, poder-se-ia contrapor o objeto analisado àquilo que seria do âmbito da natureza, dividindo as respectivas práticas observáveis em suas ligações e características naturais ou culturais. Ou seja, natureza e cultura complementar-se-iam na formação do universo estudado, sem jamais estarem completamente justapostas.

Desse modo, por exemplo, religião, parentesco, folclore, arte, organizações, burocracia, ciência e liderança seriam elegíveis campos de estudo em cultura. Isso pelo fato de se tratar de tecnologias sociais, respostas desenvolvidas pela criação humana frente a dificuldades práticas derivadas de problemas sociais específicos. A cultura tem, ainda, "poder" de criar fronteiras identitárias a partir do conjunto de papéis que compõem os grupos assim formados. As ligações dessa ordem permitem segmentar, analiticamente, a realidade 
observada. Ela poderia então ser analisada em termos de sua reprodução simbólica/entendimento de um lado e, de outro, material/funcional.

Todavia, o que mais impressiona os egressos de outras disciplinas, que procuraram alento para suas inquietações advindas de problemas reais em mudança organizacional, se refere ao método de pesquisa: a etnografia. Aqui, o cerne de nossa proposta.

Em termos gerais, o método ajuda na identificação do objeto de estudo e seu recorte. Assim, pode-se destacar e explicar aquilo que é característico de uma cultura específica, sempre em termos relativos, em comparação a outras (vertical) ou no tempo (horizontal). Enquanto método, a etnografia permite deixar em segundo plano aquilo que seria comum a todas as civilizações já estudadas, assim destacando a cultura da natureza.

Trabalhos anteriores demonstraram que investir numa metodologia que complemente o conjunto relacional relevante, a partir do funcionalismo vigente, pode traduzir interessante contribuição às políticas institucionais. Um caminho que trilha a compreensão de características e necessidades apontadas pela gestão local como significantes. Algo que vem permitir, aos dirigentes, uma intervenção mais qualificada na realidade gerenciada, ao eliminar alguns custos, materiais e morais, advindos de mudanças de rumo tidas como necessárias. O desenvolvimento da "etnografia customizada" trilha o caminho sugerido. Nele, a partir das descrições funcionais encontradas no lócus de pesquisa, foram incorporados de forma seletiva outros elementos conceituais explicativos - linguisticalidade, intencionalidade, normatividade, consensualidade e estrategicidade. Todos, potencialmente, são formadores complementares dos contextos de ação das estruturas locais (D’ASCENZI, 2006, 2010) .

Este artigo não trata, portanto, de crítica teórica em si - esta não falta à TGA -, mas de uma proposta de interlocução e continuidade a partir de práticas hegemônicas concretas. Elas foram ilustradas através de Chiavenato (1999), que expõe teorias seguramente apartadas e apresentadas com ares de totalidade, como se nada mais houvesse. Entretanto, tal característica é recorrente em termos hegemônicos.

Do mesmo modo, tendo em vista nossa necessidade de entendimento e interlocução, outros manuais e compêndios consultados não fogem a isso. Dessa maneira, Motta e Vasconcelos (2009) fazem apresentação "desenvolvimentista", em termos evolutivos, do padrão mais simples ao mais complexo, deixando o leitor apressado com a impressão de tratar-se de alguma ciência natural, mas o mais persistente pode corrigir tal sensação, ao notar a falta de diálogo entre os paradigmas apresentados; Clegg, Hardy e Nord (1999, 2001, 2004) coordenam coletânea útil em Teoria das Organizações, mas marcadamente segmentada e, assim, igualmente emblemática; ainda mais notório nessa característica, Morgan (1996) propõe método de análise que integra modelos por meio de diferentes "visões da organização", contudo, sem jamais misturá-las, mas uma "metáfora" de cada vez. Portanto, há uma inequívoca utilização ostensiva e única do elemento conceitual funcionalista por parte das visões hegemônicas da TGA, o que vem estabelecer limites práticos a suas explicações.

\section{CONSIDERAÇÕES FINAIS}

Este trabalho perscrutou a formulação do conceito de cultura organizacional na TGA traduzida e consubstanciada em práticas empresariais. Assim, realizou-se um exame da "novidade", que teria surgido no âmbito das necessidades de reestruturação organizacional, como movimento adaptativo ao contexto competitivo trazido pelas fortes mudanças sociais ocorridas a partir dos anos 1970. Procurou-se resgatar o surgimento da temática, já na década 
de 1980, até sua consolidação pelas teorias do Desenvolvimento Organizacional, que estariam embasadas por matrizes teóricas comportamentalistas. Buscou-se então, entender suas possibilidades e seus limites.

Quanto às possibilidades, não há como minimizar o potencial prático-explicativo das abordagens funcionalistas em contextos organizacionais. A sobrevivência da empresa passa, antes de tudo, pela reprodução das estruturas internas, porém, suas formulações têm pouca utilidade em face da problemática da mudança de processos e estruturas organizacionais. A partir desse ponto, sugere-se o desenvolvimento de soluções que incorporem mais elementos conceituais, em direção ao conceito de cultura encontrado no escopo da antropologia social, área que originou os primeiros estudos em cultura.

Afinal, este estudo em cultura organizacional percebeu foco excessivo na instrumentalidade operacional, remetendo tanto ao "etnocentrismo" cultural quando em análises comparativas, quanto à "reificação" da cultura quando no planejamento de intervenções. Ambos aparecem como reflexo de visões behavioristas, exclusivamente funcionalista. Assim, a superação dessa amarra demandaria incorporar discussões em "relativismo cultural", de resto uma fase ultrapassada de longa data pelas Ciências Sociais. O movimento abriria espaço à percepção de outras possibilidades de referência e vigor para as grandezas organizacionais pesquisadas. Assim, a revisão bibliográfica da TGA hegemônica permite concluir pela precariedade da transposição da teoria para o campo da prática administrativa. Provavelmente, uma lacuna formada por revisão bibliográfica insuficiente em "cultura", quando de sua incorporação.

Dessa maneira, em termos qualitativos, pareceu ocorrer desenvolvimento paralelo, disciplinarmente marcado, mas, independente do "estado da arte" em antropologia social, que não se vale dos avanços e tropeços ali sofridos e assimilados. A temática haveria começado em consequência da incorporação crescente do "ambiente" externo à organização. Com o tempo, tais propostas teriam superado o status de modismo, tornando-se precursoras dos estudos em cultura organizacional. Eles, por sua vez, caminharam para uma "quaseespecialização", embora vinculados a uma única operacionalidade prática, as pesquisas em clima organizacional. Concluímos que essa "outra-origem-tardia-independente" dos estudos em cultura, somada ao pouco cuidado teórico-metodológico, pode consubstanciar explicação para os tropeços revividos em análises culturais sob a égide da TGA.

Por seu turno, a antropologia social tem se dedicado desde sua formação à compreensão das dimensões culturais do comportamento social humano, contando pelo menos um século e meio de pesquisas sobre diversidade cultural. Isso vem apontar para o respeito às descobertas precedentes, passíveis de aplicação no entendimento da dinâmica cultural em contextos organizacionais.

Nosso diálogo indicou que, para ser clarificada, a cultura não poderia ser pensada como uma resultante da reprodução de espécies naturais, ligadas direta e exclusivamente a funções específicas. Ao contrário, tal dinâmica só ocorre porque as estruturas sociais têm aspecto múltiplo, e apenas por isso ganham relevância explicativa. Melhor ainda, que tais condicionantes estruturais podem ser estudadas e apreendidas utilizando-se um esforço de distinção em práticas e seus respectivos contextos. Um exercício metodológico empreendido, de longa data, pela etnografia e por seus desdobramentos, busca maior conformação às especificidades do lócus de pesquisa.

Para tanto, frisa-se a necessária adaptação contextual, prévia à ampliação conceitual, especialmente útil em gestão de mudanças. Por um lado, a partir de um corpo teórico adequado, que permita trabalhar com a premissa de que mudanças ocorram o tempo todo, de 
que nesse exato momento incontáveis estruturas sociais estão se reproduzindo sob esse risco intrínseco a toda e qualquer cultura.

Por outro lado, e já no âmbito da TGA, adviria uma necessária valoração e utilização da diversidade de padrões culturais locais. Isso poderia contribuir para o processo de objetivação da intencionalidade da gestão, hoje pressionada entre as necessidades de inovação e os programas de qualidade. Afinal, é à gestão que caberia a difícil tarefa de contornar as questões relativas à reprodução das estruturas locais e a seus respectivos processos, com ou sem mudanças, ao mesmo tempo, mantendo-os economicamente eficazes e tecnicamente eficientes. Portanto, é um possível ponto de partida, que aponta para as peculiaridades da TGA a partir do método etnográfico, especificamente desenvolvido.

Enfim, as pesquisas indicam certos consensos em Ciências Sociais, e não caberia a uma ciência (ou arte) aplicada contestá-los. Assim, a TGA precisaria incorporar a visão de que a cultura mais se assemelha a uma complexa estrutura de significados que os indivíduos tecem historicamente por meio das suas interações cotidianas e que dá sentido à vida coletiva, funcionando como um código que informa o comportamento: uma espécie de mapa para a ação. Essa ideia, que não é nova, é válida para qualquer agrupamento humano, incluindo suas instituições, independentemente do grau de formalização dos grupos estudados. Portanto não faz sentido tratar a cultura como elemento de mudança, mas de condicionamento do comportamento humano.

$\mathrm{Na}$ verdade, mesmo a cultura sendo um elemento de conservação das estruturas sociais, as possibilidades de mudança permanecem em aberto, posto haver "risco" intrínseco a cada reprodução dessas mesmas estruturas, tensionadas em meio à diversidade de padrões que coabitam os espaços organizacionais. Tal probabilidade se abre cada vez que elas são ativadas em toda reprodução estrutural empiricamente observada. É nesse espaço, entre os diversos graus de permanência e mudança, que a gestão pode encontrar seu universo de intervenção, num movimento que, efetivamente, venha a acelerar o processo de humanização e democratização das relações de trabalho, enquanto categoria histórica originada na Idade Antiga, época em que estava associada à tortura e à escravidão.

As possibilidades de aplicação das teorias e dos métodos consolidados em Ciências Sociais, em geral, mas particularmente em cultura, dar-se-iam por meio de uma gama de possibilidades: desde o monitoramento e/ou a avaliação pontual, frente a alguma categoria construída e segmentada da realidade organizacional a partir de demandas específicas da gestão (D'ASCENZI, 2010), até o acompanhamento detalhado de todo o emaranhado de sistemas sociais que importam a uma organização em particular, mais aos moldes de uma etnografia típica (RUBEN, 2004). O último caso é uma promessa de modelagem e de incorporação ainda inédita.

Contudo, a validade do caminho apontado, de incorporação do cabedal antropológico, passa pela atividade de pesquisa e desenvolvimento de tecnologias sociais aplicáveis à formatação de novas ferramentas gerenciais num movimento que busque aliar os demais elementos conceituais presentes na ação social e complementares às análises funcionalistas internas ao campo da Teoria Geral da Administração. Com isso, a percepção dos contextos de ação organizacional ganharia em objetividade e sustentabilidade, algo que pode representar mais uma distinção entre violência e gerência de instituições. Senão, é melhor ficar com o velho jargão: "teoria na prática é outra". 


\section{REFERÊNCIAS}

ANDRADE, T. N. Tendências da inovação: estudo sociológico sobre o gerenciamento das tecnologias. São Carlos: Pedro \& João Editores, 2011.

OLIVEIRA, R. C. Sobre o pensamento antropológico. Rio de Janeiro: Tempo Brasileiro, 1988.

CHIAVENATO, I. Introdução à Teoria Geral da Administração. São Paulo: Makron Books, 1999.

CLEGG, S. R.; HARDY, C.; NORD, W. R. Handbook de estudos organizacionais, v. 1. São Paulo: Atlas, 1999.

Atlas, 2001. Handbook de estudos organizacionais, v. 2. São Paulo:

Atlas, 2004. Handbook de estudos organizacionais, v. 3. São Paulo:

COHEN, M. D.; MARCH, J. G.; OLSEN, J. P. A Garbage Can Model of Organizational Choice. Administrative Science Quarterly, v. 17, n. 1, 1972.

COLOMBO, J. Teles perdem US\$ 65 bi com investimentos malsucedidos. Valor, São Paulo, v. 13, n. 3093, p. B3, 14 set. 2012.

COOMBS, R.; SAVIOTTI, P.; WALSH, V. Economics and Technological Change. London: Macmillan Press, 1987.

D’ASCENZI, L. Cultura e Mudança em Organizações: Uma análise etnográfica e dialógica da reestruturação promovida pelo Método da Roda nos centros de saúde de Campinas/ SP. Dissertação (Mestrado em Antropologia Social) - Universidade Estadual de Campinas, Campinas, 2006.

. Cultura e inovação em organizações: proposta de desenvolvimento etnográfico a partir de estudo em elos da cadeia de valor de uma pequena software house de Campinas/SP. Tese (Doutorado em Ciências Sociais) - Universidade Estadual de Campinas, Campinas, 2010.

DEAL, T.; KENNEDY, A. Corporate Cultures. New York: Perseus, 1982.

DEMING, W. E. Qualidade: a revolução da Administração. Rio de Janeiro: MarquesSaraiva, 1990.

FERGUSON, C. E. Microeconomia. 7. ed. Rio de Janeiro: Forense-Universitária, 1984.

FOUCAULT, M. Vigiar e punir. 2. ed. Petrópolis: Vozes, 1983.

GEERTZ, C. A interpretação das culturas. Rio de Janeiro: Zahar, 1978. O saber local. Petrópolis: Vozes, 2002.

GIDDENS, A. Política, sociologia e teoria social. São Paulo: Unesp, 1997.

HOFSTEDE, G. Culture's consequences: international differences in work-related values. Beverly Hills: Sage, 1980.

KROEBER, A. L.; KLUCKHOHN, C. Culture: a critical review of concepts and definitions. New York: Vintage Books, 1963.

GєCont, v. 1, n. 2, Floriano-PI, Jan-Jun. 2014. 
MORGAN, G. Imagens da organização. São Paulo: Atlas, 1996.

MOTTA, F. C. P.; VASCONCELOS, I. F. G. Teoria Geral da Administração. 3. ed. São Paulo: Cengage, 2009.

OUCHI, W. G. Theory Z: how American business can meet the Japanese challenge. New York: Perseus, 1981. 1981.

PASCAL, R. T.; ATHOS, A. G. The art of Japanese management. New York: Simon,

PÉPIN, N. Cultura de Empresa. Mosaico: Revista de Ciências Sociais, Vitória, v. 1, n. $1,1998$.

PETERS, T. J.; WATERMAN, R. H. In search of Excellence. New York: Harper Collins, 1982.

RUBEN, G. R. Empresários e globalização. Revista Brasileira de Ciências Sociais, $\mathrm{n}$. 28, jun. 1995. Disponível em: 〈http://www.anpocs.org.br/portal/publicacoes/rbcs_00_28/rbcs 28_07.htm>. Acesso em: 12 nov. 2013.

RUBEN, G. R. (Org.). Dossiê: Etnografias do Capitalismo Brasileiro. Ideias, v. 11, n. 3, 2004.

SAHLINS, M. Ilhas de História. Rio de Janeiro: Zahar, 1990.

SCHEIN, E. Organizational culture and leadership. San Francisco: Jossey-Bass, 1985.

SIMON, H. A. Comportamento administrativo. Rio de Janeiro: Editora da FGV, 1979. (mimeo.).

SOTO, E. Comportamento organizacional. São Paulo: Thomson Pioneira, 2005.

TIDD, J.; BESSANT, J.; PAVITT, K. Managing innovation. UK: Wiley, 2001.

VARIAN, H. R. Microeconomia. 3. ed. Rio de Janeiro: Campus, 1993.

VASCONCELLOS, M. A. S. Economia micro e macro. 4. ed. São Paulo: Atlas, 2009.

WOOD, T. (Org.). Mudança organizacional. São Paulo: Atlas, 1995.

\footnotetext{
${ }^{1}$ Estes chegam a pôr em xeque a autoridade etnográfica, a autoria do texto e a cientificidade dos relatos. Ilustrativamente, ver Clifford (2002).

2 Tradução livre: O que nós chamamos de "inovação"? Essencialmente, referimo-nos a mudanças, particularmente às tecnológicas. Estas mudanças podem tomar duas formas - nas coisas (produtos/serviços) que uma organização oferece, e mudança nos modos pelos quais elas são criadas e fornecidas.

${ }^{3} \mathrm{O}$ estudo realizado pela consultoria PriceWaterHouseCoopers (PWC), em janeiro de 2012, tomou como amostra 78 empresas de telecomunicações e de TV a cabo de todo o mundo. "O levantamento mostrou que o crescimento expressivo dos recursos foi acompanhado por um baixo retorno sobre o investimento, com média de 3 pontos percentuais abaixo dos custos para a obtenção do capital para o investimento. Assim, as operadoras gastaram 9\% para captar o dinheiro para o investimento, sendo que o retorno obtido foi de $6 \%$, em média" (COLOMBO, 2012, p. 01).

${ }^{4}$ A despeito de discussões exclusivamente teóricas, estes trabalhos debruçaram-se sobre questões empíricas, no que buscaram as origens das práticas encontradas nos loci de pesquisa: os fundamentos da instrumentalidade gerencial local. O resultado foi um método de complementação aos instrumentos de gestão em uso, cujas conclusões foram apropriadas pela direção local através de laudos utilizados em planos estratégicos e de reestruturação.
} 